\title{
AGE AT MENARCHE: DIFFERENTIALS AND DETERMINANTS
}

\section{ABSTRACT}

This paper is an attempt to investigate the differentials and determinants of age at menarche according to the characteristics of females. Simple average, univariate as well as multivariate analysis were carried out. A multivariate technique has been utilized to study the effect of various socio-economic variables on the timing of menarche.

The data for this study were taken from a sample survey of Palpa and Rupandehi Districts" conducted between January and June 2000. A total of 1258 (including 239 daughters and 1019 mothers) females provided information on the age at menarche. For this study only 239 samples of young girls have been analysed.

Mean age at menarche was found about 15 and 14 years for older generation (mothers) and younger generation (their daughters) respectively. A decreased age at menarche was found with the increased level of socio-economic status group of girls. Age at menarche was found higher for girls belonging to nonschooling (15.7 years) as compared to the schooling girls (14.2 years). It was found that the variables 'socioeconomic status', and 'caste/ethnicity' were the significant determinants for the timing of menarche. A higher risk of getting menarche early was found for high socio-economic status and schooling girls as compared to the low socio-economic and non-schooling, which may be due to nutrition and physical and psychological stress during the early childhood.

\section{Key Words: Fertility, Menarche, Differentials, Determinants, Reproductive, Adolescent, Sub-fecundity, Foetal wastage.}

\section{INTRODUCTION}

The reproductive lifespan of a woman begins with the onset of menstruation i.e. menarche and it continued till the cessation of menstruation i.e. menopause. Age at menarche have received relatively a little attention in the existing demographic literature, which may perhaps be due to the lack of reliable data as well as the lack of interest among the researchers.

There is a significant variation in the age at menarche around the globe within and between the populations. ${ }^{1,2}$ The highest ages of menarche are found among New Guinea tribes, rural Bangladeshis, rural Rwandans and the nomadic Dobe Kung, which ranges from about 15 to 19 years whereas the lowest ages are found among well-off urban and developed populations, which ranges from about 12 to 14 years., Numerous investigations have found a slightly decline trend in the mean age at menarche over time and the average amount of decrease has been about two months per decades. ${ }^{5,6}$ After menarche, there is also wide variation among societies in the intermediate fertility variables, particularly in the age at entry into sexual union and the use of contraception and abortion. ${ }^{7}$

Address for correspondence : Dr. Tika Ram Aryal

Central Department of Statistics

Tribhuvan University, Kirtipur, Kathmandu, Nepal

Email: traryal@rediffmail.com 
The onset of the menarche is a signal of the maturity and readiness for marriage. However in some populations marriage may occur before menarche. ${ }^{1}$ Nutritional status is markedly recognized as one of the most important non-genetic determinants of onset of menstruation and several evidences have been given in demographic literature ${ }^{8,9,10}$ Several studies have found a direct relationship between diet and menarche. ${ }^{11,12}$

It has also been assessed that the physical and psychological stress during early childhood leads to advancement in the reproductive maturation among girls. ${ }^{13}$ Age at menarche affects fertility through the length of the reproductive life span, adolescent sub-fecundity, and foetal wastage. Women with early menarche have had shorter birth interval and higher lifetime fertility. ${ }^{14}$ Age at menarche plays an important role in deciding the level of fertility in a society. ${ }^{1}$ In Nepal, not adequate work has been done on age at menarche despite its direct relationship with fertility and woman health.

\section{OBJECTIVE}

The objective of this paper is (i) to find out the average age at menarche, and (ii) to identify the factors affecting the age at menarche. Accordingly, mean age at menarche has been computed according to different characteristics of females. A multivariate technique has been utilized to study the effect of various socio-economic variables on the timing of menarche.

\section{MATERIALS AND METHODS}

The data for this study have been taken from a sample survey entitled "Demographic Survey on Fertility and Mobility (DSFM) in Rural Nepal: A study of the Palpa and Rupandehi Districts" conducted between January and June 2000. A total of 811 households were surveyed. A sample of all ever-married women as well as their daughters under aged 55 years was interviewed. Besides, information on socio-economic, demographic and cultural variables, the data on age at menarche were also collected. Each and every eligible woman was asked whether she had menarche. If the answer was yes, the woman was asked the age at menarche. In the survey a total of 1566 females' ages of 12-55 years were obtained. Out of 1566 females, a total of 1258 females (1019 ever-married mothers and 239 daughters) had attained menarche. There were 308 girls who have not attained menarche at the time of interview. The variables, all measured at the survey date, are grouped into three categories: demographic, socio-economic and cultural variables. Demographic variable included age at menarche measured in the completed years. Education, occupation, social status, economic status, land ownership, type of household, residential status of the women are included in the socio-economic variables group. Cultural variables included caste/ethnicity. Various variables and measurements are found in Aryal. ${ }^{1}$

The differentials in age at menarche have been discussed in relation to some socio-economic and cultural characteristics of females. For this purpose, mean age at menarche, univariate and multivariate analysis have been worked out. Univariate hazard model analysis provided a measure of the effect of each variable on the attainment of menarche (hazard function) in the absence of control for other variables. A multivariate analysis is utilized to examine the effect of each category of each variable on hazard function while controlling for the effects of other variables along with their categories included in the model. The survival time was treated as dependent variable and the associated variables as independent variables. Cox proportional hazard model technique was used in data analysis. ${ }^{15}$

\section{RESULTS}

In the survey, out of 1258 , a total of 239 daughters also provided information on the timing of menarche on or before the survey date. Table I presents mean age at menarche according to various background characteristics of females for both the generations (mother and daughter). It was found that the age at menarche declined from 15.0 years (older generation) to 14.3 years (younger generation) and the amount of decline was about eight months. The lower age at menarche among the younger generation may perhaps be associated with increased stature and improved diet over time. Since several studies have reported relationships among nutritional status, menarche and fertility. ${ }^{16}$

Mean age at menarche for older generation was found to be 15.0, 14.8 and 14.6 years respectively for low, middle and high social status group of females while it was 14.5, 14.4 and 13.7 years for the respective social status group of females of the younger generation. It was found that the mean age at menarche did not differ significantly for older generation according to the characteristics of females. This may perhaps be due to socio-economic status, which is generally changed over time. Another reason may be due to memory lapse for recalled their menarche among the older generation. But there is no such memory lapse for younger generations. Hence the differentials and determinants of age at menarche have been investigated by taking the data of younger generation (daughters). Since the younger generation has no such memory lapsed for recalling their menarche. Hereafter we discuss only the younger generation.

A significant difference was found in the mean age at menarche for girls who belong to low (14.8 years) and high (13.7 years) 
Table I : Mean age at menarche according to the characteristics of females (mother and daughter)

\begin{tabular}{l|c|c|c}
\hline \multirow{2}{*}{ Characteristics of females } & Number of cases & \multicolumn{2}{|c}{ Mean } \\
\cline { 2 - 4 } & & Mothers* & Daughters \\
\hline Social status & 92 & 15.38 & 14.82 \\
Low & 58 & 15.02 & 14.48 \\
Middle & 89 & 14.75 & 13.72 \\
High & & & \\
\hline Economic status & 76 & 15.21 & 14.84 \\
Low & 97 & 15.17 & 14.28 \\
Middle & 66 & 14.71 & 14.33 \\
High & & & \\
\hline Landholdings & 43 & 15.57 & 14.94 \\
Landless & 59 & 15.48 & 14.60 \\
Marginal & 78 & 14.94 & 14.23 \\
Small & 59 & 14.42 & 13.74 \\
Big & & & \\
\hline Caste/ethnicity & 104 & 14.87 & 14.27 \\
Brahmin & 70 & 15.14 & 14.39 \\
Chhetri & 65 & 15.37 & 14.54 \\
Others (Magar, Gurung, & & & \\
Tharu, Choudhary, etc.) & & & \\
\hline Schooling & 215 & 14.91 & 14.18 \\
Schooling & 24 & 15.92 & 15.67 \\
Non-schooling & & & \\
\hline Household type & 129 & 14.59 & 13.98 \\
Nuclear & 110 & 15.37 & 14.74 \\
Joint & 93 & & \\
\hline Residence & 146 & 15.58 & 14.77 \\
Hill & $\mathbf{2 3 9}$ & $\mathbf{1 5 . 0 6}$ & $\mathbf{1 4 . 3 3}$ \\
Tarai & & & \\
\hline & & & \\
\hline
\end{tabular}

* calculated from the females (mothers) corresponding to daughters given in the last two columns

Table II : Univariate hazard model analyses for the age at menarche

\begin{tabular}{l|c|c|c|c}
\hline \multicolumn{1}{c|}{ Characteristics of females } & $\mathbf{- 2 L o g L}$ & Chi-square & d.f. & p- value \\
\hline Social Status & 2256.34 & 16.18 & 2 & $0.0002^{*}$ \\
\hline Economic Status & 2265.30 & 7.25 & 2 & $0.0270^{*}$ \\
\hline Landholdings & 2263.84 & 8.68 & 3 & $0.0338^{*}$ \\
\hline Caste/ethnicity & 2267.78 & 4.76 & 2 & 0.0983 \\
\hline Schooling & 2265.76 & 6.77 & 1 & $0.0093^{*}$ \\
\hline Household type & 2263.97 & 8.56 & 1 & $0.0034^{*}$ \\
\hline Residence & 2268.43 & 4.10 & 1 & $0.0429^{*}$ \\
\hline \multicolumn{5}{|c}{ significant }
\end{tabular}

social status $(Z=4.29 ; \mathrm{p}<0.01)$. Age at menarche according to 'economic status' showed a similar pattern as that of 'social status', and a significant difference in the mean age at menarche between low and high economic status group of girls was also observed $(z=4.47 ; \mathrm{p}<0.01)$. A significant difference in the mean age at menarche between girls with 'landless' (14.9 years) and 'big land holdings' (13.7 years) was observed $(\mathrm{Z}=5.36 ; \mathrm{p}<0.01)$.

Mean age at menarche was found 14.5 years for other caste groups (Damai, Kami, Newar,Tharu, Choudhary, etc.) whereas it was 14.3 and 14.4 years for Brahmin and Chhetri caste females respectively. Age at menarche was found 14.2 and
15.8 years for schooling (at least 5 years education) and nonschooling girls respectively and the difference was found significant $(\mathrm{z}=5.24 ; \mathrm{p}<0.01)$. A significant difference was found in the mean age at menarche for girls belong to nuclear (14.0 years) and joint (14.7 years) household type ( $\mathrm{z}=3.14$; $\mathrm{p}<0.01)$. Mean age at menarche was found slightly higher among girls residing in Hills (14.8 years) as compared to those living in Tarai (14.1 years) $(\mathrm{z}=3.12 ; \mathrm{p}<0.01)$, which may be due to ecological and climatic effects.

Univariate analysis indicated that the variables viz: landholding, socio-economic status, residence, household type and schooling status have a significant effect on the timing of 
Table III : Multivariate Cox proportional hazard model analysis of age at menarche

\begin{tabular}{|c|c|c|c|c|}
\hline Characteristics & $\begin{array}{c}\text { Estimated } \\
\text { Co-efficients (B) }\end{array}$ & S.E. & p- value & $\begin{array}{l}\text { Relative Risk } \\
\operatorname{Exp}(\mathbf{B})\end{array}$ \\
\hline \multicolumn{5}{|l|}{ Social Status } \\
\hline Low & - & - & - & 1.0000 \\
\hline Middle & 0.1916 & 0.1778 & 0.2811 & 1.2112 \\
\hline High & 0.4802 & 0.1643 & $0.0035^{*}$ & 1.6165 \\
\hline \multicolumn{5}{|l|}{ Economic Status } \\
\hline Low & - & - & - & 1.0000 \\
\hline Middle & 0.078 & 0.1666 & 0.6450 & 1.0798 \\
\hline High & 0.4818 & 0.1885 & $0.0106^{*}$ & 1.6190 \\
\hline \multicolumn{5}{|l|}{ Landholdings } \\
\hline Landless & - & - & - & 1.0000 \\
\hline Marginal & 0.2157 & 0.2101 & 0.3044 & 1.2410 \\
\hline Small & 0.1635 & 0.2078 & 0.4314 & 1.1778 \\
\hline Big & 0.3252 & 0.2198 & 0.1391 & 1.3841 \\
\hline \multicolumn{5}{|l|}{ Schooling } \\
\hline Schooling & - & - & - & 1.0000 \\
\hline Non-schooling & 0.4317 & 0.2010 & $0.0498 *$ & 1.6399 \\
\hline \multicolumn{5}{|l|}{ Household type } \\
\hline Nuclear & - & - & - & 1.0000 \\
\hline Joint & -0.1347 & 0.1470 & 0.3592 & 0.8740 \\
\hline \multicolumn{5}{|l|}{ Residence } \\
\hline Hill & - & - & - & 1.0000 \\
\hline Tarai & 0.0088 & 0.1749 & 0.9597 & 0.9912 \\
\hline \multicolumn{5}{|c|}{-2log likelihood $=2272.53 ;$ Model } \\
\hline
\end{tabular}

menarche (Table II). Table III shows the estimated coefficients along with standard error and level of significance from the Cox's proportional hazard model. While carrying out the multivariate analysis, insignificant variables were excluded. A relative risk of 1.00 indicates the baseline or reference category for each variable. The relative risk greater (less) than 1.00 indicate high (low) risks of attainment of menarche than the reference category.

A multivariate analysis suggests that the variables 'socioeconomic status' and 'schooling' were the significant determinants on the timing of menarche.

The regression coefficient was significant for high socioeconomic status girls and 1.6 times higher risk of getting menarche early was found for this category as compared to girls of low socio-economic status. About 36 per cent less risk of getting menarche early was found for non-schooling girls as compared to schooling girls. A higher risk of getting menarche early for schooling girls may be due to physical as well as psychological stress during early childhood. The variables, 'household type', 'landless' and 'residence', were found insignificant. However, about 13 per cent less risk of getting menarche early was found for girls belonging to joint household as compared to nuclear households. Similarly, 1.4 times higher risk of getting menarche early was found for girls also belong to big landholdings category.

\section{DISCUSSION}

The study showed some specific results. Mean age of menarche, estimated for Nepalese females at about 15.0 years (Table I), is later than among well-off urban and developed populations, which ranges from about 12 to 14 years and considerably earlier than among New Guinea tribes, rural Bangladeshis, rural Rwandans and the nomadic Dobe Kung, which ranges from about 15 to 19 years. ${ }^{3,4}$ The study also showed that the variables viz: landholding, socio-economic status, residence, household type and schooling status have a significant effect on the timing of menarche (Table II). Two principle explanations can be offered for the reproductive advantages of early maturing females, relating respectively to attitudinal factors and physiological development. ${ }^{12,17}$ An initial postponement of reproduction gives a female the opportunity to lower her fertility preferences, which may perhaps be due to the experiences of education and employment offer sources of satisfaction other than motherhood. Hence the family sizes are deliberately chosen as a consequence of socioeconomic experiences that delay reproduction process.

A study also showed that higher levels of stress among intact families were associated with earlier age at menarche, which is consistent results. ${ }^{18}$ It is noted that delayed menarcheal age in nutritionally and socially deprived groups as compared both between and within contemporary populations. ${ }^{12,17}$ There is 
strong evidence that high socioeconomic status is positively associated with early menarche. Nepalese evidence is consistent with the argument that menarcheal timing is associated with nutritional status where early maturing females come from richer family who enjoy a greater availability of good food than others. ${ }^{1}$ This study indicated that the higher risk of getting menarche early was found for high socio-economic status girls and schooling girls, which may be due to nutritional, physical and psychological stress during early childhood (Table III).

It is indicated that early maturing females got married early consequently early gave first birth. In Nepal, unless female proves her fertility, her socio-cultural status, is not improved in the household and society. Childlessness is regarded as a curse on woman. ${ }^{19}$ Thus it is natural for a bride to improve her status as well as her autonomy by producing children as soon as possible.

\section{CONCLUSIONS}

Mean age at menarche was found about 15 and 14 years for older generation (mothers) and younger generation (their daughters) respectively. A decreased age at menarche was found with the increased level of socio-economic status. Age at menarche was found highest for low social status girls (14.8 years) followed by middle (14.5 years) and high (13.7 years).

It was found that the variables 'socio-economic status' and 'schooling status' were the significant determinants for the timing of menarche. About twice times higher risk of getting menarche early was found for high socio-economic status girls as compared to that of low socio-economic status group girls. A less risk of getting menarche early was found for nonschooling girls and it was about 36 per cent less risk as compared to the schooling status girls, which may be due to physical and psychological stress during early childhood.

\section{ACKNOWLEDGEMENT}

I would like to express my sincere gratitude to Professor KNS Yadava, Centre for Population Studies, Department of Statistics, BHU, India, for his help in preparing this paper.

\section{REFERENCES}

1 Aryal TR Sone denographi c nodel $s$ and the $r$ appl i cati ons with reference to Nepal. Unpuld i shed Ph D thesi S, Banaras Hndu Uversity, Inda 2002

2 Thonas F, Renaud F, Benefi ce E Neus TD and Gregan J F. Internati ond variability of ages at nenerche and nenopause: patterns and nai $\mathrm{n}$ deterninants. Human Bi ol ogy. 2001; 73(2) : 272-290.

3 Becker $S$ The deterniments of add escent ferti i ity vith speci d reference to bidogical variaddes. Ed ted by Gray $R$ Leridan $H$ and Spi ra A in B oned cal and Denographi c Determinants of Reproducti on Carendon Press Of ord. 1993: 50-64.

$4 \quad$ Evel eth PB and Tanner J M Vorl d w de vari ati ons in hunan growth. Canbri dge Uni versi ty Press, Canbri dge 1976.

5 Prado C Secul ar change in nenarche in wonan in Madri . Annal s of Huan Bi ol ogy. 1984; 11(2) : 165-6.

6 Wyshak $G$ Secul ar changes in age at nenarche in a sanpl e of US vonen Annal s of Hunan Bi ol ogy. 1984; 10(1) : 75-7.

7. Lavis $\$$ andBake J. Sodal strunture and fetility. an and ytic franework. Econonic Devel opnent and Cul tural Change. 1956; 4(4) : 211-35.

8 Marshal I WA and Tanner M Puberty. Edi ted WA Marshal I and J M Tanner. Hunan Grouth, $2^{\text {nd }}$ edn. Pl enumPress, London. 1986 : 171- 209

9 Wyshak G and Fri sch RE Evi dence of a secul ar trend in age at nenarche. New Engl and of J ournal of Nedi ci ne. 1982; 306(17) : 1033-5

10. Varea C, Berris C, Mutero P, Aris S, Barroso A and Congal es B Seal ar trends and i tra populati and variability in age at nenopause in Spsni s vonen. J ournal of B o-soci al Sci ence 2000; 32 : 383-393.

11 Nakanura I, Shi rnora M Nbnakand $\mathrm{K}$ and Mura T. Changes of recol I ected nenarcheal age and nonth anong wonan in Tokyo over a peri od of 90 years. Amal s of Hunan Bi ol ogy. 1986 13(6) : 547-54

12. Urdy JR and $\mathrm{Q}$ i quet R A cross-cultural exanination of the rel ati onshi $p$ between ages at nenarche, narri age and fi rst bi rth. Denography. 1982; 19(1): 53-63

13. Conbel I BC and Utry J R Stress and age at nenarche of nothers and daughters. J arnal of B o-social Sci ence 1995; 27: $127-134$.

14. R l ey AP, Sanud son $J L$ and Hiffnan $S$ The rel ati onshi $p$ of age at nenarche and ferti l i ty in undernouri shed adbl escents. Ed ted by Gray R Leri don Hand Spi ra A in B oned cal and Denographic Deterninants of Reproducti on $\mathrm{O}$ arendon Press Oford. 1993 : 50-64.

15. Cox RD Regressi on nodd s and li fe tables (vith d scussi an)... J arnal of Royd Statistical Society, Series-B 1972, 34: 178 202.

16. Rana T, Rahnan L, Rau P and Rao KV. Associ ati on of growth stat us and age at nenarche in urban upper nidd e i ncone grap girls of Hyderabad I nd an J arnal of Nad cal Research 1986; 84 : 522- 30.

17. Mul der MB. Nenarche, nenopause and reproducti on in the Kipsigis of Kenya. J arnal of B o-social Sci ence 1989, ZZ: 179-92.

18. Surbey MK Fanil y composition stress, and hunan nenarche In: Soci oendocri nol ogy of Pri nate Reproducti on. Edi ted by Z eg er TE and Bercovitch FB VIl ey-Liss, NewYork. 1990 : 11-32.

19. Nral a $\mathrm{B}$ The soc oeconoric context of high fertility in rura Nepal: The case of Beni ghat. Uhpubl i shed Ph. D thesi s, Australian Nati and Ui versity, Crberra, Australia 1991 